\title{
Evolving your semantics: Feedback between data projects and the corporate standard
}

\author{
John Jordan \\ is a senior data analyst in the Siemens Business Services' Media Data Consultancy. He is a senior member of the team \\ providing a data management service to the $\mathrm{BBC}$ and has just lead the media asset management strand of a project \\ implementing an end-to-end production, playout and archiving system in the BBC World Service.
}

Keywords: digital asset management (DAM), data analysis, data management, corporate semantic standard, system development

\begin{abstract}
Paradoxically, in the current rapidly changing business environment it has never been more important to maintain a standard view of the meaning of the business data within an organization. Only with a common corporate understanding of the semantics of the data can the organization hope to develop the interoperating systems environment which will maximize the value of their assets and minimize the effort required to use them. Maintaining the shared semantics within an agile organization in a rapidly changing business environment is complex and this paper describes a method for doing just that. It will also outline the value of the corporate model, how it is used, derived and maintained, and the value and role of projects in this activity.
\end{abstract}

John Jordan

Senior Data Analyst

Siemens Business

Services

G201 Stadium House

68 Wood Lane

London W12 7TA

UK

Tel: $+44(0) 7739$

920023

Fax: +44 (0) 208576

3029

Email:

johnjordan@siemens.com

\section{THE IMPORTANCE OF DATA}

Unless an organization knows what its assets are, where they are, what they can do with them and how much that will cost, it cannot do business effectively.

The metadata underlying this information are, increasingly, being shared across the organization databases are no longer merely the province of the team that created them.

As the data gain wider currency it becomes crucial that we have a common, pan-organization understanding of what that data actually mean - the organization needs a semantic standard.

\section{THE VALUE OF A SEMANTIC STANDARD}

This paper describes a general approach to the development and evolution of a corporate data standard. The methods and processes described are informed by the activities of an outsourced data team working for the British Broadcasting Corporation (BBC) to provide a data management service known as the Data Integration Service (DIS). One of the component parts of the DIS is the maintenance of the BBC's corporate semantic model.

The DIS data team takes an approach which uses the existing business system development projects to enhance and 
renew the corporate standard. This project-based approach ensures that the corporate standard evolves in the same direction and at the same rate as the business: ensuring system interoperability and supporting the chosen commercial strategy.

As, in general, these activities require that an organization has both the will to impose a corporate standard and the resource to develop and maintain the standard, it is best to state clearly why the organization is doing this.

This can be done quite simply — the goal is to gain business benefit by enabling media asset management:

- simplifying asset exchange and reuse;

- enabling information sharing by breaking down data silos;

- informing the provision of systems which are fit for purpose - no matter whether they're developed in-house, purchased packages, or leased services.

\section{WHAT FORMAT DOES THE STANDARD TAKE?}

The core of the data team's activity is the development and maintenance of the corporate semantic data model (CSDM). This model represents and defines the meaning of things of interest to the business and of the business rules which link them. Examples of these things in a broadcasting environment would include programs, playlist items, transmissions, contributors, rights, etc.

This model can be presented in a variety of ways but, for ease of maintenance, it should be managed in a computer aided software engineering (CASE) tool. The tool, in general, will limit the presentation of the model to one or other of two styles - entity relationship diagrams (ERD) and class models in unified modeling language (UML). More advanced tools will allow the generation of XML schemas from selected areas of the model.

It is worth stressing that, for the purposes of the corporate semantic model, the style of presentation (ERD vs UML) is one of mere preference. The point is the clear and unambiguous representation of the meaning to the business of the data and of the relationships between the data.

Figure 1 provides an example of one of the ERDs used to represent the BBC's corporate semantic model ${ }^{1}$ - the BBC Standard Media Exchange Framework, $\mathrm{SMEF}^{\mathrm{TM}}$. The blocks (entities) represent the objects of interest to the business and the lines between them, the business relationships. Each entity has a number of named data attributes which represent those of the object's properties which are of interest to the business.

The colored entities contain reference data and are candidates for the data team's reference data management activities. We will mention reference data later but, here, it is sufficient to note that the CSDM can be used to bring together several strands of the organization's data management activities.

The simplest way of representing the data structures and relationships is graphically, but the definitions are communicated in a data dictionary. The data dictionary is associated with the figures and contains a detailed definition of every data element - entities, attributes and, increasingly, relationships. Figure 2 is an example of a data dictionary entry for one of the $\mathrm{SMEF}^{\mathrm{TM}}$ entities on the ERD. Each entity is 


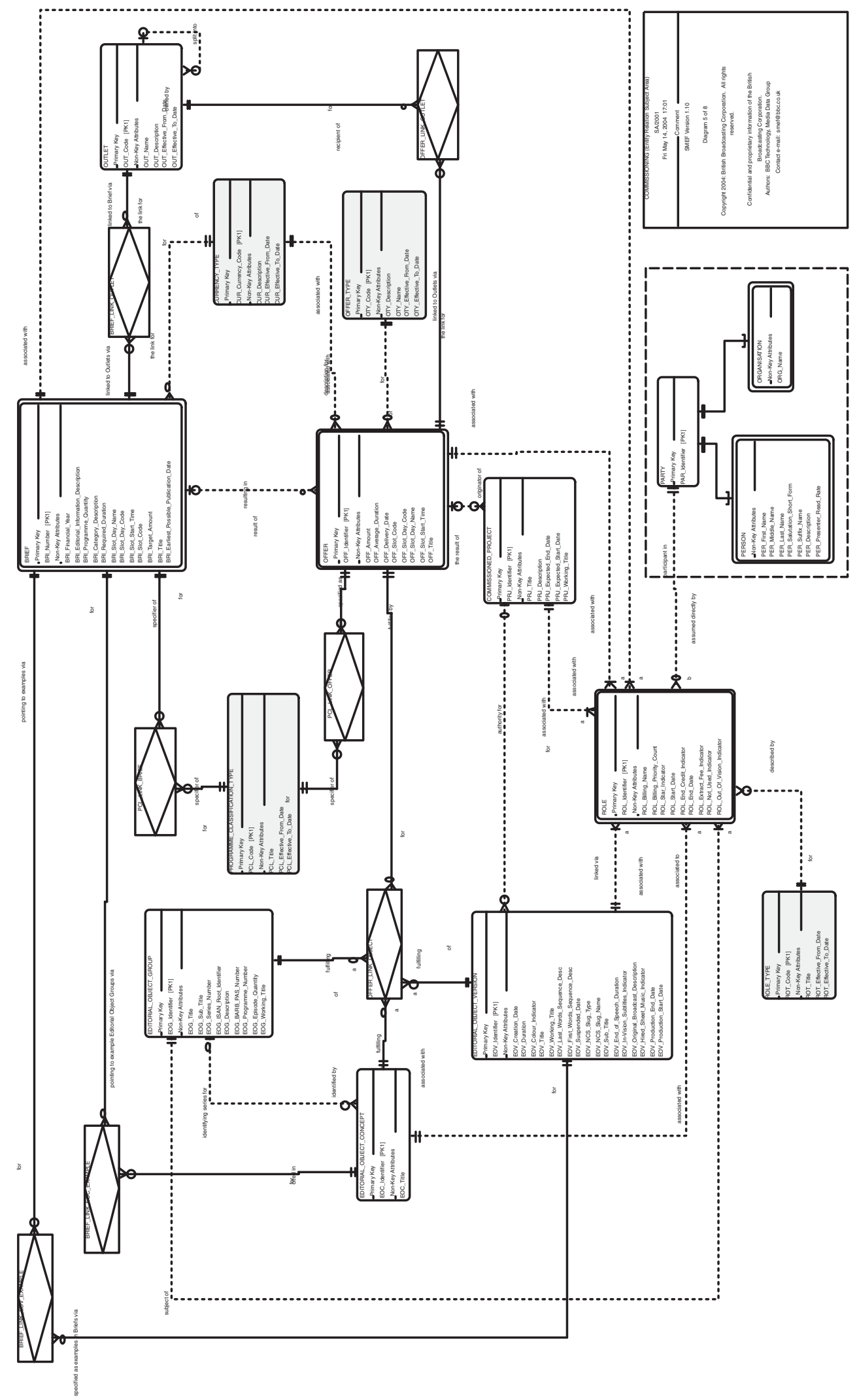

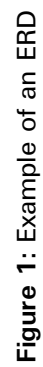




\title{
EDITORIAL_DESCRIPTION_TERM_ASSOCIATION
}

\author{
Appears on diagrams: \\ v1.10_Diag_5_COMMISSION_EDITORIAL_GENRE_AND_DESCRIPTION \\ Abbreviation: EDA
}

This records an association between two editorial description scheme terms. The association may be between terms from the same description scheme or the terms may be from different schemes.

An example of an association between terms in the same description scheme may be that describing a term as a subset of a wider term. In this case, for example, Children's Drama may be a special type of Drama.

\begin{abstract}
An example of an association between terms in different description schemes may be a mapping indicating that two terms, one from each of the two different description schemes, are to be thought of as being, to some degree, semantically similar. The degree of similarity will vary with the most similar being, effectively, identical. For example, the BBC Editorial Category term 6:45:17 (FACTUAL : HUMAN INTEREST : TECHNOLOGY) may be similar to the DSAT genre term 3015 (TECHNOLOGY).

EDA_Effective_From_Date

EDA_Effective_To_Date

The first date from which an Editorial Description Term Association is valid for new Editorial Description Term. For example, if an Editorial Description Term Association has a start date of 12 August, 1998, then it may be applied to the Editorial Description Term from and including that day.

The last date on which an Editorial Description Term Association is valid for new Editorial Description Term. For example, if an Editorial Description Term Association has an end date of 12 August, 1999, then it may be applied to the Editorial Description Term on that day, but not on the following day. The Editorial Description Term Association remains in the system for historical data.
\end{abstract}

Relationships To:

**EDITORIAL_DESCRIPTION_TERM_ASSOCIATION must be the link for one EDITORIAL_DESCRIPTION_TERM **EDITORIAL_DESCRIPTION_TERM_ASSOCIATION must be the link for one EDITORIAL_DESCRIPTION_TERM **EDITORIAL_DESCRIPTION_TERM_ASSOCIATION must be categorised by one EDITORIAL_DESCRIPTION_TERM_ASSOCIATION_TYPE

Figure 2: Example of a data dictionary entry

described in terms that include business examples where possible.

One of the strengths of the semantic approach is that it allows the data management team to remain technology-agnostic and for the individual projects to select the implementation technology which fits their situation best.

A final point when considering the representation of the model is that it should be appropriate to the situation. It is sometimes forgotten, but every model can be expressed at different levels of precision ${ }^{2}$ and taking a highly detailed model, intended for a technical audience, into a general business usergroup meeting can be counterproductive.

\section{HOW THE STANDARD PROVIDES VALUE}

The thinking behind the standard is quite simple - effective sharing of information requires that we have a common understanding of what data items mean. If different business communities understand data to mean different things then the data are, at best, useless and, at worst, dangerous.

Using a well accepted definition of an asset as: Asset $=$ Content + Metadata $^{3}$ it 
becomes clear that unreliable metadata transform an asset into a liability.

For the purposes of this paper, the terms data and metadata will be used interchangeably to mean the same thing. The metadata to be managed will include the data structures of business systems, descriptive data (both editorial and physical) about media assets and corporate reference data sets. Reference data may be defined as any kind of data used to categorize other data found in a database or for relating data in a database to information beyond the boundaries of a particular system or the enterprise. ${ }^{4}$ Examples of corporate reference data will include the descriptive taxonomies used within an organization to classify their assets: examples of taxonomies would include catalog indexing terms and content genres.

The development of a shared, semantics-based data architecture will allow effective inter-system communication, the development of a corporate approach to the implementation of external data standards such as television Anytime and P-Meta, and the adoption of a pansystems approach to integration.

This paper will concentrate on the management of the business systems' data architecture rather than on the maintenance of taxonomies.

\section{THE STANDARD AS A SEMANTIC BUS}

An increasingly common example of a pan-systems integration architecture is the use of middleware-enabled web services within organizations. The development of shared exchange messages is a prerequisite for the implementation of a services oriented architecture (SOA).

Within such an environment, the corporate standard acts as a semantic bus - a common communication layer used and understood by the systems within the organization. Thus, developers can do away with individually developed point to point interfaces and replace them with agreed exchanges through the
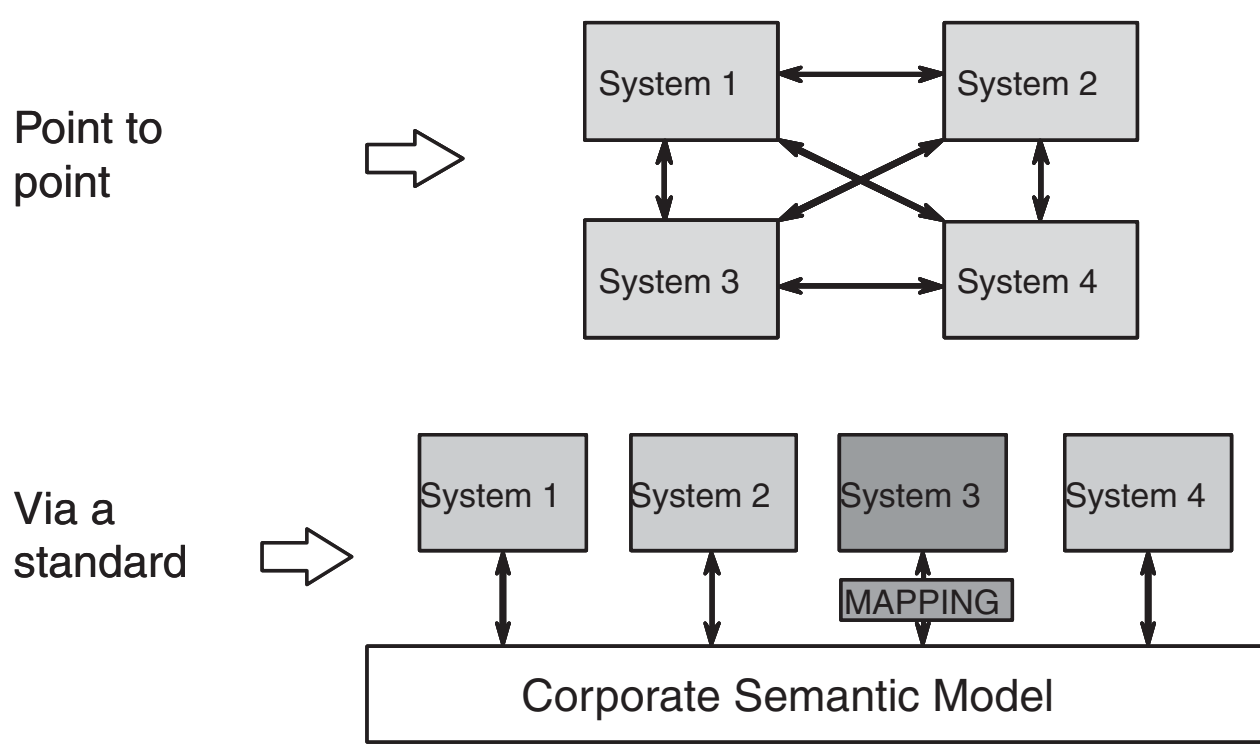

Figure 3: Point-to-point or standards enabled interfaces 
medium of the common data standard (Figure 3). This allows independent development of specific individual systems within the organization by simplifying system integration.

\section{WHO MANAGES THE STANDARD?}

The team that manages the standard need not be large. Small organizations, with a relatively specialized business, don't need a team as large as that required by a national or international radio and television broadcaster with a large web presence. A data team can be as small as a single person.

Management of the corporate semantic standard will be one of several functions that the group provides. Other, related functions could include:

- Setting up the business organization and processes to enable the organization to manage its reference data efficiently: for example, avoiding divergence of meaning within the corporate reference data and maintaining its integrity supporting data sharing.

- Defining and managing data stewardship policies: data stewardship can be defined as being accountable for the definition of the quality of a set of data such that it supports all required uses by the organization. Data stewardship means also being responsible for the delivered level of data quality. It is about the quality of corporate data and not, for example, how or where it is stored.

- Managing the corporate exchange model: providing a model and supporting specifications of the actual messages and interfaces used to exchange data within the organization.

As can be seen from the examples of the tasks performed by the data management team, the aim of their activities is to increase data sharing, data quality and data reliability across the organization. The team will be composed of data analysts and architects and can be provided internally from the company or can be an outsourced service working under a service level agreement.

An organization of the size and complexity of the $\mathrm{BBC}$ would require about eight full-time staff to maintain the entire DIS activity. Of this team, some two and a half are sufficient to maintain the corporate semantic standard and carry out the project mapping and compliance activities. The same level of activity could be carried out in a smaller organization by a proportionately smaller team.

\section{BUSINESS DIRECTION: GOVERNANCE, TECHNICAL STRATEGY AND A DATA CHARTER}

For any corporate data standard to be successful, it is critical that the organization impose a system of governance upon the design and use of its data. No matter whether the data management team are in-house or outsourced, in order for their activities to be effective they must work to a senior technical strategy group within the client organization. The reasons for this are related to the two organization requirements we mentioned at the beginning of this paper - the will to impose a corporate standard and the resource to maintain it.

By taking the role of customer for the data management service, the organization's technical strategy group indicates that the service is a corporate policy with high-level support. The data 
management team's role should be stated and defined by the publication of a data charter. This data charter, adopted by resolution of the management board, should establish the rationale and context for the development and delivery of the pan-organization approach to data integration. It should set out how this is to be delivered, who is involved, what they will produce and how it will be managed.

The second main reason for working to a senior technical strategy group is that the data management team is certain to be resource-limited and will be unable to work with all the systems under development within the organization. Because of this, it is crucial that the business' technical strategy group should identify the high priority developments for the attentions of the data management team.

One method, commonly used to impose governance upon an organization's data, is for all system development projects over a specified size to be referred to the technical strategy group for review and appraisal. When selecting projects for compliance to the corporate model, the group would have a clearly defined remit:

- to minimize technical investment costs across the organization;

- to ensure the investment provides best value for money;

- to ensure the investment is in line with the organization's published technical strategy;

- to mandate that any development project will comply with organizational technical standards and policies.

In essence, the technical strategy group ensures that projects of strategic value to the organization are delivered in a consistent and cost effective manner.

It must be stressed that this is not just an academic technical exercise - it cannot be forgotten that the technical strategy group is, essentially, representing the business and the goal is the procurement of technology to fit with business strategy and to gain business benefit.

By giving the technical strategy group the authority to mandate compliance to the corporate data standard as a prerequisite for funding, we can ensure that the corporate data standard will be present in all the major strategic developments. It should also be remarked that compliance to the corporate standard in selected strategic systems has a noticeable cascade effect, moving compliance, informally, into projects not specifically selected for compliance.

\section{WHAT IS THE ROLE OF PROJECTS?}

At their best, projects represent the movement of the business in the direction the business strategy has chosen. By working with projects, the data management team has the ability to influence the development of the system environment for the future. Setting modeling directions to achieve compliance during the project analysis phase - avoiding re-work and retrofitting - minimizes overhead to the business.

The project team should not slavishly adopt the corporate model - they must carry out additional analysis. This additional analysis will test the corporate model against reality - giving us increased confidence in the corporate standard. 
The project analysis is the prime source of accurate business definitions for the data structures and relationships as they are used within the scope of the project.

A point which shouldn't be underestimated is the political value of working with the business during the project and using the business to enhance and develop the corporate standard. If this is handled well it can foster a sense of "ownership" within the business as they see their understanding reflected back into the standard.

\section{HOW DOES THE DATA TEAM WORK WITH PROJECTS?}

It is hugely important that the compliance process should have a minimal negative impact upon the project. To this end, although the project will fund its own project analysis, the compliance exercise can be funded centrally. A useful way to simplify the compliance reviews is for the project to employ one of the data team as a project data analyst and for the same data team member to carry out the compliance mappings and reviews.

After a project has been selected for compliance a member of the data team will meet with the project manager to agree a modeling approach and the review timetable. The selection of the compliance sign-off points will be tailored to the development method used. Figure 4 illustrates a fairly standard project lifecycle comprising four phases: inception, elaboration, construction and transition. The middle row contains examples of the sort of project documentation we would expect to see generated at each stage. The bottom row gives examples of the points at which it would be natural for the data team to schedule compliance reviews.

The scheduling of compliance reviews at each of the points illustrated in Figure 4 would be severe overkill for all but the largest and most complex projects and would probably be construed as harassment. As a minimum, however, we would expect the project's statement of data requirements to be compliant with the corporate standard and then to have a further review stage

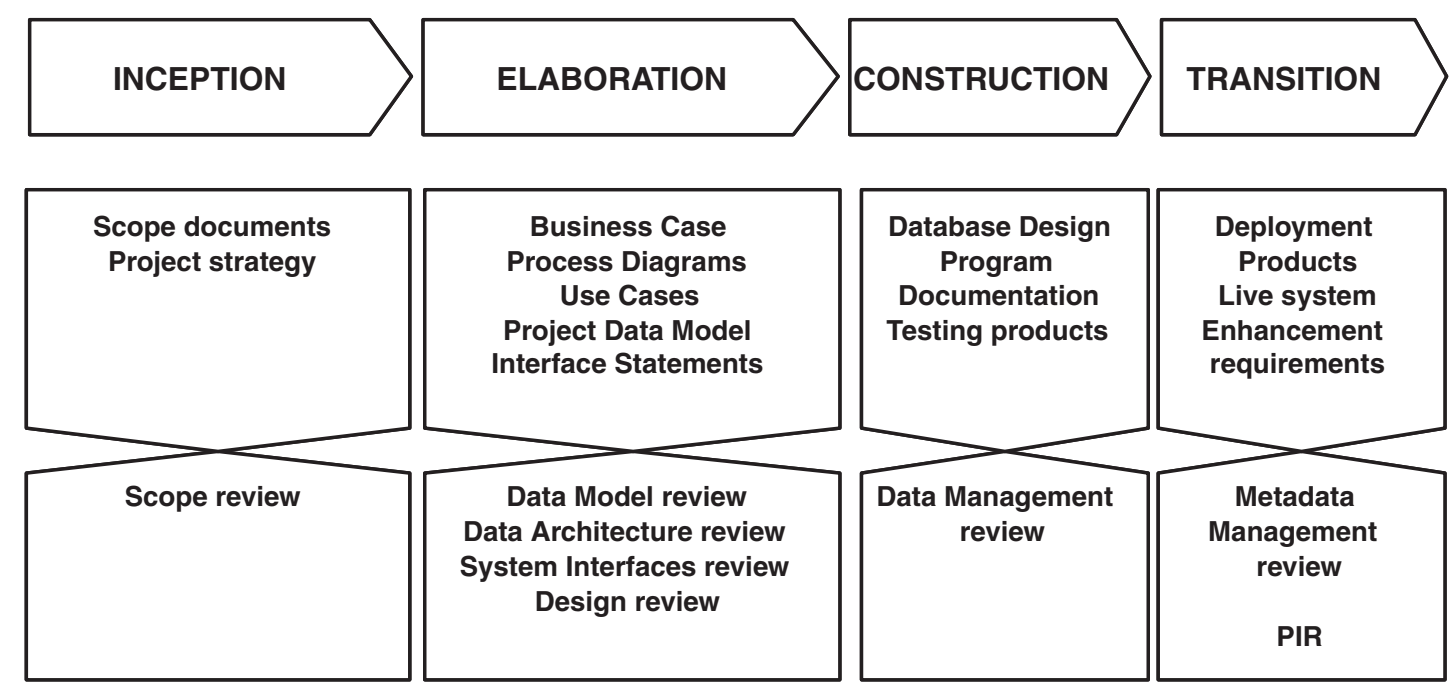

Figure 4: Example project lifecycle 
at the end of the construction phase to ensure that the delivered system meets the stated requirements.

It is also recommended that, when the project has been delivered, and the system moves into the maintenance and enhancement phase (not illustrated), further routine compliance meetings are scheduled in order to ensure that the system's compliance to the corporate standard is not threatened by maintenance modifications. These compliance meetings need not be scheduled in the sense of setting a date but can be made part of the system's configuration management approach.

Although the example of the project lifecycle in Figure 4 is for a software development project, it is possible to apply the principles to both package purchase schemes and leased services. In each of these cases the requirement need not be for the internal system structure to comply with the standard but for the compliance to apply to the supplied system's interfaces. The requirement for compliant interfaces can be used as one of the system selection criteria.

It is extremely unlikely that any system scope will encompass all of the data areas represented on the corporate model. The next step after agreeing the review points is, therefore, for the data team to supply the project with the relevant subset of the corporate model. This provides the project with a rapid start to their analysis phase and ensures that the project's model starts with a compliant core. The value of this to the project in terms of saving analysis time should not be underestimated.

As the project carries out its own analysis it will enhance and modify the supplied data model to produce its own data requirements' definitions. These requirements may be expressed in a variety of ways but one of the most common is by the development of a project logical data model (PLDM). The PLDM expresses the proposed system's data requirements in a formal manner and satisfying the PLDM can be one of the project's deliverables. Another advantage of the use of a standard method like the PLDM is that it makes it very easy to compare a project's data definitions with the corporate standard and/or another project's model.

The rest of this paper will be based on the used of a PLDM to express the project's data requirements, but as long as the project's data requirements are expressed clearly and unambiguously, the same principles apply to any representation.

During the development of the project's data requirements the data structures can diverge from the corporate standard and this is where the value of having a data team member on the project as an analyst or the data team being represented at design workshops can be most obvious.

\section{WHAT IS COMPLIANCE?}

There are two main types of criteria for the assessment of compliance of a PLDM to the corporate standard: modeling quality criteria and semantic mapping criteria.

The aim of the first group of criteria is to ensure that the project's data requirements are expressed clearly and consistently. These are presentation quality standards for the PLDM and they include measures such as:

- Are the entities appropriate to the business area?

- Are entities, attributes and relationships 
named clearly, unambiguously, appropriately and in agreement with corporate model naming conventions?

- Are business examples included?

- Are relationship names consistent with the cardinality and optionality?

Other formal methods for stating the data requirements will have functionally similar measures of quality.

The second group - containing the semantic criteria - is rather more fun. Here the measure is the degree to which the PLDM data structures and concepts are semantically related to the structures and concepts within the corporate model. To enable this judgment to be made, one of the data team will produce a document which attempts to map each appropriate PLDM object (entity, attribute and relationship) to a similar object on the corporate standard.

The word "appropriate," in the previous sentence, is used to make a particular point. Not all data elements and structures on the PLDM need be compliant with the standard. If we remember that the point of the standard is to enable the reuse and exchange of assets and of information about assets, we can see that any given system is likely to contain data which fall outside the standard's remit: system specific data and/or purely administrative data. The corporate standard need not concern itself with data of this sort and to attempt to map them would be a waste of resources.

The semantic criteria are quite complex and form an intricately interdependent rule set but some of the simpler measures include:

- Can each PLDM entity/attribute/ relationship be mapped to an entity on the standard? If not, should a new entity/ attribute/relationship be created on the standard?

- Are the PLDM object descriptions identical to the corporate standard? If not, do they simply represent a more constrained definition of a generic corporate description with contradiction of the standard?

- Are the cardinality, optionality and exclusivity of the PLDM relationships consistent with their representation on the standard?

At the conclusion of the mapping there will be two outcomes:

- A list of new project-related knowledge of data structures and elements, not currently present on the corporate standard, will be available for consideration for inclusion on the standard.

- A decision as to whether the PLDM and, by extension, the specified system can be mapped successfully and unequivocally to the corporate standard, enabling the proposed system to use standard interfaces with other systems in its environment.

\section{COMPLIANCE DECISION}

It is the responsibility of the data team to report back to their client, the business technical strategy group, the compliance status of the selected projects. The decision as to whether or not a system is compliant lies with the data team but the actions following on from the report are the responsibility of the technical strategy group.

The report back to the client can include an analysis of the impact of any non-compliant areas. This impact 
analysis will allow the strategy group to makes estimates of the cost-benefit of any remedial work.

\section{FEEDBACK FROM THE PROJECT TO THE STANDARD}

As we have seen, one of the outcomes of the project compliance review will be a list of the new business knowledge obtained from the project and not currently on the standard. This knowledge is then used to help develop the standard. Figure 5 illustrates this project-standard interaction.

The feedback, from the projects into the corporate standard, means that the standard will change over time. The modifications to the standard might be as minor as the enhancement of a particular entity definition to include a business example specific to one area of the business. It might, on the other hand, involve a major restructuring of the corporate standard to include analysis from a completely new business area. To minimize the chance of such a major revision it is critical that the business is widely consulted on the content and meaning of the standard.

The good news is that the more mature the standard, the less likely that major upheaval is to be expected.

\section{CHANGE MANAGEMENT OF THE STANDARD}

Given that the standard is changing over time it is important to have a change management process in place. The process need not be complex but it should be formal and rigorous. An outline of the change control process for $\mathrm{SMEF}^{\mathrm{TM}}$ within the $\mathrm{BBC}$ is as follows:

1. As part of the project mapping and compliance work, suggested modifications to SMEF $^{\mathrm{TM}}$ are added to a change log with supporting documentation.

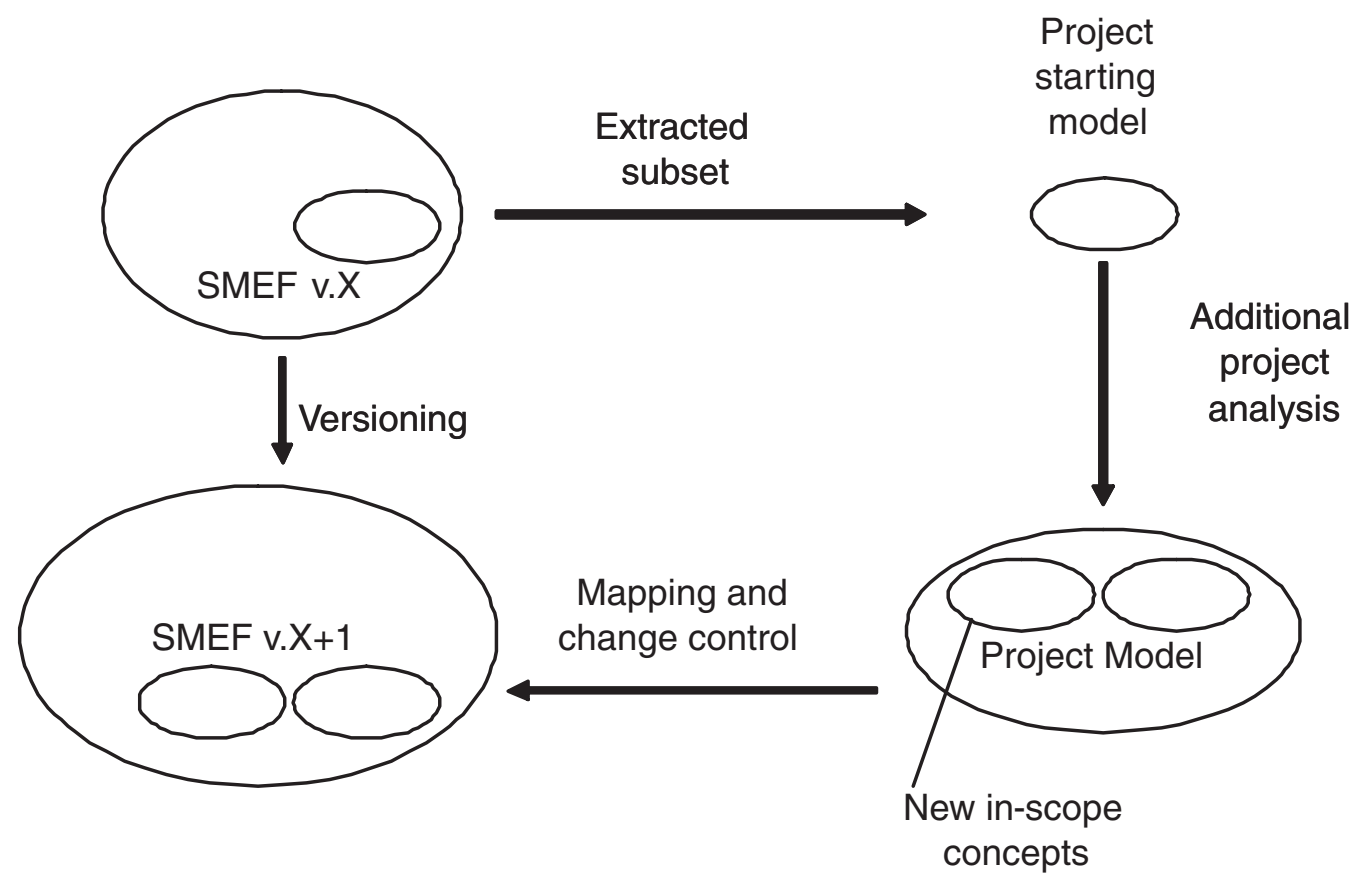

Figure 5: Project-standard interaction 
2. As part of a regular version publication cycle, existing change log entries are grouped into business areas reflecting the data structures involved and assigned to a member of the data team for analysis, including impact analysis and recommendation.

3. The analyst prepares their recommendations in consultation with the business and these recommendations are debated at a workshop. Where possible, the workshop should include both members of the data management team and business representatives. The inclusion of the business minimizes the chance of false analysis leading to a future major restructuring of the model and helps the model get business buy-in.

4. The decisions from the workshop are recorded in the change log with additional supporting documentation.

5. Successful recommendations are incorporated into the next version of SMEF $^{\mathrm{TM}}$ which is then published with a relevant change log extract.

6. The audit trails of the relevant data structures in the $\mathrm{SMEF}^{\mathrm{TM}}$ model within the CASE tool are modified to reflect the changes and to ensure traceability. Confidence in the model's validity is increased by knowing the model's derivation and the reasons for any change.

\section{VERSIONING AND MAPPING THE STANDARD}

It is as vital to map between versions of the corporate standard as it is to map between the standard and the PLDM. Only if we understand the direct relationships between the versions of the standard can we make statements about the indirect relationships between PLDM, which have been mapped to different versions of the standard (Figure 6).

To facilitate this sort of analysis the PLDM and the SMEF $^{\mathrm{TM}}$ versions are

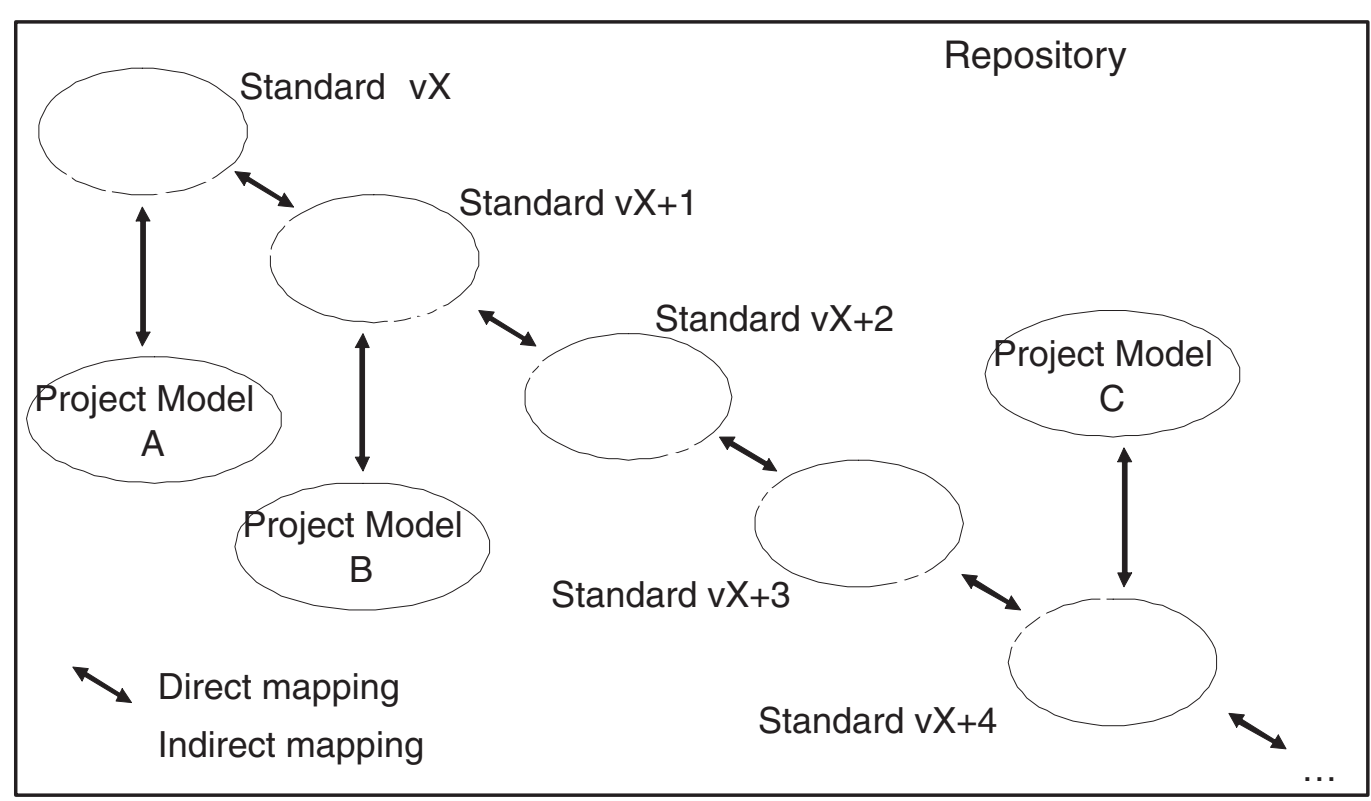

Figure 6: Mappings across versions of the standard 
held within a repository tool which also contains the mapping tables between the various PLDM and SMEF ${ }^{\mathrm{TM}}$ models. As SMEF $^{\mathrm{TM}}$ evolves, the tool allows mappings to be maintained between previously mapped project models and the current version of the standard. The tool also enables impact analyses as the data standard evolves and is versioned and/or modifications are proposed to the PLDM for an existing system during an enhancement program. These impact analyses inform the cost-benefit decisions made by the business technical strategy group.

\section{CONCLUSIONS}

We have seen that a corporate semantic standard can simplify the reuse of assets and information across an organization. The development of this standard is complex and requires both resolution and resource - but it is achievable. The standard's management process must be designed to take into account both the strategic aims of the organization and the business' need for agility and flexibility. By doing this, we can ensure that the corporate standard evolves in a controlled manner to take account of business and organizational change. In the end, the simplification of media asset management brings business benefit.

Of course, the possession of a robust corporate semantic standard isn't sufficient (on its own) to bring this about. The organization requires a strategic implementation strategy to make use of this semantic standard. That, however, is another story

\section{ACKNOWLEDGMENTS}

The author would like to thank the $\mathrm{BBC}$ for allowing reference to, and illustration from, the $\mathrm{SMEF}^{\mathrm{TM}}$ model. Thanks are also due to colleagues within both the BBC and Siemens Business Services for help and support as this paper was written and during the dayto-day activity of the Data Integration Service. Finally, thanks are due to "the business" for their input into the development of $\mathrm{SMEF}^{\mathrm{TM}}$ and the fun as we've all worked to deliver it. $\mathrm{SMEF}^{\mathrm{TM}}$ is a trademark of the BBC.

\section{References}

1. BBC (2004) Standard Media Exchange Framework - SMEF ${ }^{T M}$ Data Model, v1.10.

2. Booch, G., Rumbaugh, J. and Jacobson, I. (1999) The Unified Modelling Language User Guide. Addison Wesley, Reading, MA.

3. Marcus, I. (2005) "The DAM vendor landscape: What the buyer should know." Journal of Digital Asset Management, Vol. 1, No. 1, pp. 46-58.

4. Chisolm, M. (2001) Managing Reference Data in Enterprise Databases, Morgan Kaufmann, San Francisco, CA. 